\title{
TINGKAT KEPUASAN PASIEN TERHADAP PELAYAN OBAT DI PUSKESMAS BARAKA KECAMATAN BARAKA KABUPATEN ENREKANG
}

\author{
Santi Sinala*), Hiany Salim*), Nindia Reski Ardilla*) \\ ${ }^{*}$ Jurusan Farmasi Poltekkes Kemenkes Makassar
}

\begin{abstract}
ABSTRAK
Telah dilakukan penelitian di Puskesmas Baraka Kecamatan Baraka Kabupaten Enrekang yang bertujuan untuk mengetahui tingkat kepuasan pasien terhadap pelayanan obat di Puskesmas Baraka. Penelitian ini adalah penelitian deskriptif dengan menggunakan kuesioner sebagai instrument pengumpulan data. Hasil penelitian menunjukkan bahwa tingkat kepuasan pasien terhadap pelayanan obat di Puskesmas Baraka Kecamatan Baraka Kabupaten Enrekang dalam kategori puas $(68,6 \%)$. Data yang diperoleh diolah dengan menggunakan Skala Likert, yaitu untuk jawaban sangat puas diberi nilai 4 , puas diberi nilai 3 , cukup puas diberi nilai 2 , tidak puas diberi nilai 1. Hasil penelitian pada lima dimensi kualitas pelayanan diperoleh presentase skoryaitu kehandalan $=66,4 \%$ (puas), daya tanggap $=67,7 \%$ (puas), jaminan $=69,2 \%$ (puas), ,epedulian $=$ $66,7 \%$ (puas), bukti fisik $=72,9 \%$ (puas).
\end{abstract}

\section{Kata kunci : Pelayanan Obat, Kepuasan Pasien.}

\section{PENDAHULUAN}

Tersedianya pelayanan kesehatan yang berkualitas bagi masyarakat menjadi hal yang harus mendapat perhatian dari pemerintah sebagai salah satu upaya dalam pembangunan di bidang kesehatan. Pelayanan kesehatan kepada masyarakat bertujuan membentuk masyarakat yang sehat, maka diperlukan upaya-upaya kesehatan yang menyeluruh dan terpadu untuk mencapai tujuan pembangunan kesehatan tersebut (Siregar, 2003).

Pada pelayanan kesehatan, obat merupakan komponen yang penting karena diperlukan dalam sebagian besar upaya kesehatan untuk menghilangkan gejala dari suatu penyakit, mencegah penyakit, serta dapat menyembuhkan penyakit. Tetapi di lain pihak obat, dapat menimbulkan efek yang tidak diinginkan apabila penggunaannya tidak tepat. Oleh sebab itu, penyediaan informasi obat yang benar, objektif dan lengkap akan sangat mendukung dalam pemberian pelayanan kesehatan yang terbaik kepada masyarakat sehingga dapat meningkatkan kemanfaatan dan keamanan penggunaan obat.

Pelayanan kefarmasian pada saat ini telah bergeser orientasinya dari pelayanan obat(drug oriented) menjadi pelayanan pasien (patient oriented) yang mengacu padaasuhan kefarmasian (pharmaceuticalcare). Kegiatan pelayanan kefarmasian yang semulahanya berfokus pada pengelolaan obat sebagai komoditi menjadi pelayanan yang komprehensif yang bertujuan untuk meningkatkan kualitas hidup dari pasien.

Sebagai konsekuensi perubahan orientasi tersebut, apoteker dan tenaga teknis kefarmasian sebagai tenaga kefarmasian dituntut untuk meningkatkan pengetahuan, keterampilan, prilaku agar dapat berinteraksi langsung dengan pasien. Bentuk interaksi tersebut antara lain adalah melaksanakan pemberian informasi, monitoring penggunaan obat untuk mengetahui tujuan akhirnya sesuai harapan dan terdokumentasi dengan baik. Tenaga kefarmasian harus memahami dan menyadari kemungkinan terjadinya kesalahan pengobatan (medication error) dalam proses pelayanan (Depkes,2006).

Puskesmas merupakan lembaga kesehatan yang pertama berhadapan langsung dengan pasien. Puskesmas memiliki tanggung jawab terhadap wilayah kerja yaitu suatu kecamatan. Puskesmas memiliki visi yaitu tercapainya kecamatan yang sehat. Kecamatan sehat mencakup 4 indikatorutama, yaitu hubungan yang sehat, perilaku sehat, cakupan pelayanan kesehatan yang bermutu, dan derajat kesehatan penduduk. Untuk mencapai visi tersebut 
puskesmas perlu ditunjang dengan pelayanan kefarmasian yang bermutu.

Kepuasan pasien adalah suatu tingkat perasaan pasien yang timbul sebagai akibat dari kinerja layanan kesehatan yang diperoleh setelah pasien membandingkan dengan apa yang dirasakan. Pasien akan merasa puas apabila kinerja layanan kesehatan yang diperoleh sama atau melebihi harapan (Pohan, 2006).

Puskesmas Barakamerupakan salah satu institusi pelayanan kesehatan yang berada di wilayah Kecamatan Baraka yang bertugas memberikan pelayanan kesehatan kepada masyarakat yang membutuhkan. Hal tersebut secara implisit tidaklah dapat dilepaskan dengan pelayanan kesehatan obat-obatanyang merupakan inti sari dari suatu proses pelayanan kesehatan.

Berdasarkan observasi dengan beberapa pasien yang menebus obat di Apotek Puskesmas Baraka, ada beberapa pasien yang tidak mendapatkan kebenaran informasi yang lengkap mengenai obat yang di peroleh, dikarenakan pasien di Puskesmas dengan jumlah yang tidak sedikit terutama pada hari saat masyarakat melakukan kegiatan secara bersama-sama seperti pada saat hari pasar, sehingga hal tersebut berdampak pada daya tanggap yang kurang maksimal dari pemberi layanan kepada pasien yang datang.

Berdasarkan hal tersebut, penelitian terhadap kepuasan pelayanan obat di Puskesmas Baraka Kecamatan Baraka Kabupaten Enrekang perlu dilakukan, agar pelayanan yang kurang optimal dapat diperbaiki dan pelayanan dengan nilai mutu terbaik dapat dipertahankan. Maka untuk menyikapi hal tersebut, peneliti tertarik mengangkat permasalahan ini ke dalam penelitan ilmiah.

\section{Rumusan Masalah}

Dari uraian latar belakang dapat dirumuskan masalah sebagai berikut bagaimanakah tingkat kepuasan pasien terhadap pelayanan obat di Puskesmas Baraka?

\section{Tujuan Penelitian}

Mengetahui tingkat kepuasan pasien terhadap pelayanan obat di Puskesmas Baraka Kecamatan Baraka.

\section{Manfaat Penelitian}

Manfaat penelitian ini yaitu :

1. Sebagai salah satu bahan masukan bagi Puskesmas dalam meningkatkan pelayanan kefarmasian.

2. Sebagai bahan referensi bagi tenaga farmasi untuk memperbaiki dan meningkatkan pelayanan kefarmasian serta untuk penelitian selanjutnya.

\section{METODE DAN BAHAN}

Jenis Penelitian

Jenis Penelitian ini adalah deskriptif dengan menggunakan kuesioner sebagai instrument pengumpulan data.

\section{Waktu Dan Lokasi Penelitian}

Penelitian ini dilaksanakan di Puskesmas Kecamatan Baraka Kabupaten Enrekang, dan waktu pengumpulan data dari responden dilakukan pada bulan April-Juni 2017.

\section{Populasi Dan Sampel}

1. Populasi

Populasi dari penelitian ini adalah pasien yang berobat sebanyak 770 pasien dalam waktu 1 bulan di Puskesmas Baraka Kecamatan Baraka Kabupaten Enrekang.

2. Sampel

Penarikan sampel diambil dengan menggunakan teknik Purposive Sampling berdasarkan kriteria :

a. Berumur 17 tahun keatas

b. Pernah berobat di Puskesmas Baraka minimal 2 kali

c. Bisa berkomunikasi

d. Bersedia mengisi kuesioner

e. Sudah menikah

Sampel dihitung berdasarkan Nomogram Herry King dengan tingkat kesalahan 10\% (Sugiyono, 2005). Sehingga jumlah sampel yang diambil dalam penelitian ini adalah 77 sampel di Puskesmas Baraka Kecamatan Baraka.

\section{Teknik Pengumpulan dan Pengelolahan Data}

Data primer berupa kuesioner dalam bentuk checklist yang berisikan pertanyaan dengan empat opsi jawaban dimana responden diminta untuk memilih atau menchecklist salah satu jawaban dimana setiap pertanyaan disediakan empat 
alternatife jawaban. Data diolah menggunakan skala Likert untuk jawaban sangat puas diberi skor 4, puas diberi skor skor 3, tidak puas diberi skor 2, dan sangat tidak puas diberi skor 1 .

Persentase skor

$$
=\frac{\text { jumlah skor rata }- \text { rata }}{\text { skor ideal }} \times 100 \%
$$

Skor rata-rata $=\frac{\text { nilai skor responden }}{\text { jumlah butir soal }}$

Skor ideal $=$ jumlah responden $\times 4$

Data yang diperoleh kemudian ditabulasi dan dipersentasikan berdasarkan perolahan persentase, dibagi atas 4 kategori, yaitu :

Sangat puas $\quad:>81,25 \%-100 \%$

Puas : : $>62,75 \%-81,25 \%$

Tidak puas : : $>43,75 \%-62,75 \%$

Sangat tidak puas : $>25 \%-43,75 \%$

\section{HASIL DAN PEMBAHASAN Hasil Penelitian}

Hasil penelitian yang telah dilakukan di Puskesmas Baraka Kecamatan Baraka Kabupaten Enrekang pada bulan April - Mei 2017, diperoleh data mengenai tingkat kepuasan pasien terhadap pelayanan obat di Puskesmas Baraka Kecamatan Baraka Kabupaten Enrekang. Data diperoleh dari jawaban 77 orang responden yang telah berobat minimal dua kali di Apotik Puskesmas Baraka Kecamatan Baraka Kabupaten Enrekang. Data yang diperoleh selama penelitian diuraikan berdasarkan pada setiap subvariabel yang dapat dilihat pada tabel-tabel berikut :

1. Reability ( Kehandalan ) Proses Pelayanan

Tabel 1. Frekuensi jawaban responden terhadap kehandalan petugas

\begin{tabular}{|c|c|c|c|c|c|c|c|c|c|c|}
\hline \multirow{2}{*}{$\begin{array}{c}\text { Nomor } \\
\text { Soal }\end{array}$} & \multicolumn{2}{|c|}{ Sangat Puas } & \multicolumn{2}{|c|}{ Puas } & \multicolumn{2}{|c|}{ Cukup Puas } & \multicolumn{2}{|c|}{ Tidak Puas } & \multicolumn{2}{|c|}{ Jumlah } \\
\hline & Jawaban & Skor & Jawaban & Skor & Jawaban & Skor & Jawaban & Skor & Jawaban & Skor \\
\hline 1 & 3 & 12 & 46 & 138 & 28 & 56 & 0 & 0 & 77 & 206 \\
\hline 2 & 2 & 8 & 44 & 132 & 30 & 60 & 1 & 1 & 77 & 201 \\
\hline 3 & 7 & 28 & 41 & 123 & 27 & 54 & 2 & 2 & 77 & 207 \\
\hline Jumlah & 12 & 48 & 131 & 393 & 85 & 170 & 3 & 3 & 231 & 614 \\
\hline Rata-Rata & 4 & 16 & 43.6 & 131 & 28.3 & 56.6 & 1 & 1 & 77 & 204.6 \\
\hline $\begin{array}{l}\text { Persentase } \\
\text { Skor }\end{array}$ & 5 , & & 42,5 & & & & 0,3 & & & \\
\hline
\end{tabular}

Sumber : Data Primer 2017

Tabel 1 diatas diperoleh persentase skor sebesar 66,4\% berarti kepuasan responden terhadap kehandalan atau proses pelayanan dalam kategori puas.

2. Responsiveness ( Daya Tanggap )

Tabel 2. Frekuensi jawaban responden terhadap daya tanggap petugas

\begin{tabular}{|c|c|c|c|c|c|c|c|c|c|c|}
\hline \multirow{2}{*}{$\begin{array}{l}\text { Nomor } \\
\text { Soal }\end{array}$} & \multicolumn{2}{|c|}{ Sangat Puas } & \multicolumn{2}{|c|}{ Puas } & \multicolumn{2}{|c|}{ Cukup Puas } & \multicolumn{2}{|c|}{ Tidak Puas } & \multicolumn{2}{|c|}{ Jumlah } \\
\hline & Jawaban & Skor & Jawaban & Skor & Jawaban & Skor & Jawaban & Skor & Jawaban & Skor \\
\hline 1 & 6 & 24 & 46 & 138 & 22 & 44 & 3 & 3 & 77 & 209 \\
\hline 2 & 6 & 24 & 46 & 138 & 23 & 46 & 2 & 2 & 77 & 210 \\
\hline 3 & 7 & 28 & 43 & 129 & 24 & 48 & 3 & 3 & 77 & 208 \\
\hline Jumlah & 19 & 76 & 135 & 405 & 69 & 138 & 8 & 8 & 231 & 627 \\
\hline Rata-Rata & 6.3 & 25.3 & 45 & 135 & 23 & 46 & 2.6 & 2.6 & 77 & 209 \\
\hline $\begin{array}{c}\text { Persentase } \\
\text { Skor }\end{array}$ & \multicolumn{2}{|c|}{$8,2 \%$} & \multicolumn{2}{|c|}{$43,8 \%$} & \multicolumn{2}{|c|}{$14,9 \%$} & \multicolumn{2}{|c|}{$0,8 \%$} & \multicolumn{2}{|c|}{$67,8 \%$} \\
\hline
\end{tabular}

Sumber : data Primer 2017 
Tabel 2 diatas diperoleh persentase skor sebesar 67,8 \% berarti kepuasan responden terhadap daya tanggap atau propses pelayanan petugas terhadap daya tanggap petugas dalam kategori puas.

3. Assurance (Jaminan )

Tabel 3. Frekuensi jawaban responden terhadap jaminan petugas

\begin{tabular}{|c|c|c|c|c|c|c|c|c|c|c|}
\hline \multirow{2}{*}{$\begin{array}{c}\text { Nomor } \\
\text { Soal }\end{array}$} & \multicolumn{2}{|c|}{ Sangat Puas } & \multicolumn{2}{|c|}{ Puas } & \multicolumn{2}{|c|}{ Cukup Puas } & \multicolumn{2}{|c|}{ Tidak Puas } & \multicolumn{2}{|c|}{ Jumlah } \\
\hline & Jawaban & Skor & Jawaban & Skor & Jawaban & Skor & Jawaban & Skor & Jawaban & Skor \\
\hline 1 & 4 & 16 & 48 & 144 & 24 & 48 & 1 & 1 & 77 & 209 \\
\hline 2 & 8 & 32 & 47 & 141 & 21 & 42 & 1 & 1 & 77 & 216 \\
\hline 3 & 6 & 24 & 51 & 153 & 18 & 36 & 2 & 2 & 77 & 215 \\
\hline Jumlah & 18 & 72 & 146 & 438 & 63 & 126 & 4 & 4 & 231 & 640 \\
\hline Rata-Rata & 6 & 24 & 48.6 & 146 & 21 & 42 & 1.3 & 1.3 & 77 & 213.3 \\
\hline $\begin{array}{c}\text { Persentase } \\
\text { Skor }\end{array}$ & \multicolumn{2}{|c|}{$7,7 \%$} & \multicolumn{2}{|c|}{$47,4 \%$} & \multicolumn{2}{|c|}{$13,6 \%$} & \multicolumn{2}{|c|}{$0,4 \%$} & \multicolumn{2}{|c|}{$69,2 \%$} \\
\hline
\end{tabular}

Sumber : Data Primer 2017

Tabel 3 diatas diperoleh persentase skor sebesar 69,2 \% berarti kepuasan responden terhadap jaminan petugas atau pelayanan terhadap jaminan petugas dalam kategori puas.

4. Empathy ( Kepedulian )

Tabel 4. Frekuensi jawaban responden terhadap empati pasien

\begin{tabular}{|c|c|c|c|c|c|c|c|c|c|c|}
\hline \multirow{2}{*}{$\begin{array}{c}\text { Nomor } \\
\text { Soal }\end{array}$} & \multicolumn{2}{|c|}{ Sangat Puas } & \multicolumn{2}{|c|}{ Puas } & \multicolumn{2}{|c|}{ Cukup Puas } & \multicolumn{2}{|c|}{ Tidak Puas } & \multicolumn{2}{|c|}{ Jumlah } \\
\hline & Jawaban & Skor & Jawaban & Skor & Jawaban & Skor & Jawaban & Skor & Jawaban & Skor \\
\hline 1 & 6 & 24 & 39 & 117 & 31 & 62 & 1 & 1 & 77 & 204 \\
\hline 2 & 7 & 28 & 44 & 132 & 26 & 52 & 1 & 1 & 77 & 213 \\
\hline 3 & 6 & 24 & 39 & 117 & 27 & 54 & 5 & 5 & 77 & 200 \\
\hline Jumlah & 19 & 76 & 122 & 366 & 84 & 168 & 7 & 7 & 231 & 617 \\
\hline Rata-Rata & 6.3 & 25.3 & 40.6 & 122 & 28 & 56 & 2.3 & 2.3 & 77 & 205.6 \\
\hline $\begin{array}{c}\text { Persentase } \\
\text { Skor }\end{array}$ & \multicolumn{2}{|c|}{$8,2 \%$} & \multicolumn{2}{|c|}{$39,6 \%$} & \multicolumn{2}{|c|}{$18,1 \%$} & \multicolumn{2}{|c|}{$0,7 \%$} & \multicolumn{2}{|c|}{$66,7 \%$} \\
\hline
\end{tabular}

Sumber : Data Primer 2017

Tabel 4 diatas diperoleh persentase skor sebesar $66,7 \%$ berarti kepuasan responden terhadap empati atau proses pelayanan terhadap empati dalam kategori puas.

5. Tangible ( Jaminan )

Tabel 5. Frekuensi jawaban responden terhadap jaminan pasien

\begin{tabular}{|c|c|c|c|c|c|c|c|c|c|c|}
\hline \multirow{2}{*}{ Nomor Soal } & \multicolumn{2}{|c|}{ Sangat Puas } & \multicolumn{2}{|c|}{ Puas } & \multicolumn{2}{|c|}{ Cukup Puas } & \multicolumn{2}{|c|}{ Tidak Puas } & \multicolumn{2}{|c|}{ Jumlah } \\
\hline & Jawaban & Skor & Jawaban & Skor & Jawaban & Skor & Jawaban & Skor & Jawaban & Skor \\
\hline 1 & 4 & 16 & 58 & 174 & 12 & 24 & 3 & 3 & 77 & 217 \\
\hline 2 & 8 & 32 & 58 & 174 & 10 & 20 & 1 & 1 & 77 & 227 \\
\hline 3 & 9 & 36 & 58 & 174 & 10 & 20 & 0 & 0 & 77 & 230 \\
\hline Jumlah & 21 & 84 & 174 & 522 & 32 & 64 & 4 & 4 & 231 & 674 \\
\hline Rata-Rata & 7 & 28 & 58 & 174 & 10.6 & 21.3 & 1.3 & 1.3 & 77 & 224.6 \\
\hline $\begin{array}{c}\text { Persentase } \\
\text { Skor } \\
\end{array}$ & \multicolumn{2}{|c|}{$9 \%$} & \multicolumn{2}{|c|}{$56,4 \%$} & \multicolumn{2}{|c|}{$6,9 \%$} & \multicolumn{2}{|c|}{$0,4 \%$} & \multicolumn{2}{|c|}{$72,9 \%$} \\
\hline
\end{tabular}

Sumber : Data Primer 2017 
Tabel 5 diatas diperoleh persentase skor sebesar 72,9 \% berarti kepuasan responden terhadap jaminan pasien atau proses pelayanan terhadap jaminan pasien dalam kategori puas.

Tabel 6. Frekuensi keseluruhan jawaban mengenai tingkat kepuasan pasien terhadap pelayanan obat di Puskesmas Baraka Kecamatan Baraka Kabupaten Enrekang

\begin{tabular}{|c|c|c|c|c|c|c|c|c|c|c|}
\hline \multirow{2}{*}{$\begin{array}{l}\text { Butir } \\
\text { Soal }\end{array}$} & \multicolumn{2}{|c|}{ Sangat Puas } & \multicolumn{2}{|c|}{ Puas } & \multicolumn{2}{|c|}{ Cukup Puas } & \multicolumn{2}{|c|}{ Tidak Puas } & \multicolumn{2}{|c|}{ Jumlah } \\
\hline & Jawaban & Skor & Jawaban & Skor & Jawaban & Skor & Jawaban & Skor & Jawaban & Skor \\
\hline 1 & 3 & 12 & 46 & 138 & 28 & 56 & 0 & 0 & 77 & 206 \\
\hline 2 & 2 & 8 & 44 & 132 & 30 & 60 & 1 & 1 & 77 & 201 \\
\hline 3 & 7 & 28 & 41 & 123 & 27 & 54 & 2 & 2 & 77 & 207 \\
\hline 4 & 6 & 24 & 46 & 138 & 22 & 44 & 3 & 3 & 77 & 209 \\
\hline 5 & 6 & 24 & 46 & 138 & 23 & 46 & 2 & 2 & 77 & 210 \\
\hline 6 & 7 & 28 & 43 & 129 & 24 & 48 & 3 & 3 & 77 & 208 \\
\hline 7 & 4 & 16 & 48 & 144 & 24 & 48 & 1 & 1 & 77 & 209 \\
\hline 8 & 8 & 32 & 47 & 141 & 21 & 42 & 1 & 1 & 77 & 216 \\
\hline 9 & 6 & 24 & 51 & 153 & 18 & 36 & 2 & 2 & 77 & 215 \\
\hline 10 & 6 & 24 & 39 & 117 & 31 & 62 & 1 & 1 & 77 & 204 \\
\hline 11 & 7 & 28 & 44 & 132 & 26 & 52 & 1 & 1 & 77 & 213 \\
\hline 12 & 6 & 24 & 39 & 117 & 27 & 54 & 5 & 5 & 77 & 200 \\
\hline 13 & 4 & 16 & 58 & 174 & 12 & 24 & 3 & 3 & 77 & 217 \\
\hline 14 & 8 & 32 & 58 & 174 & 10 & 20 & 1 & 1 & 77 & 227 \\
\hline 15 & 9 & 36 & 58 & 174 & 10 & 20 & 0 & 0 & 77 & 230 \\
\hline Jumlah & 89 & 356 & 708 & 2124 & 333 & 666 & 26 & 26 & 1155 & 3172 \\
\hline $\begin{array}{c}\text { Rata- } \\
\text { Rata }\end{array}$ & 5.93 & 23.73 & 47.2 & 141.6 & 22.2 & 44.4 & 1.73 & 1.73 & 77 & 211.46 \\
\hline $\begin{array}{c}\% \\
\text { Skor }\end{array}$ & 7,7 & & 45 , & & 14 & & & & & \\
\hline
\end{tabular}

Sumber : Data Primer 2017

Tabel diatas dapat diketahui bahwa tingkat kepuasan pasien terhadap pelayanan obat di Puskesmas Baraka Kecamatan Baraka Kabupaten Enrekang termasuk dalam kategori puas dengan persentase skor sebesar 68,6\%.

\section{Pembahasan}

Tingkat kepuasan pasien terhadap pelayanan obat ditentukan oleh beberapa faktor yang sangat berpengaruh dalam peningkatan kualitas pelayanan obat antara lain Reability (kehandalan), Responsiveness (daya tanggap), Assurance (jaminan), Empathy (empati), Tangibles (bukti fisik).

1. Reability (Kehandalan), yaitu kemampuan untuk memberikan pelayanan yang dijanjikan dengan tepat (accurately) dan kemampuan untuk dipercaya (dependably), terutama memberikan jasa secara tepat waktu (ontime), dengan cara yang sama sesuai dengan jadwal yang telah dijanjikan dan tanpa melakukan kesalahan setiap kali ( Jasfar, F., 2005 )

Hasil penelitian pada tabel 1 menunjukkan bahwa tanggapan responden terhadap pelayanan obat di Puskesmas Baraka Kecamatan Baraka Kabupaten Enrekang sudah merasa puas dengan jumlah persentase skor sebanyak $66,4 \%$. Hal ini dapat dilihat dari 77 responden dengan jawaban sangat puas $(5,1 \%)$, puas $(42,5 \%)$, cukup puas $(18,3 \%)$, dan tidak puas $(0,3 \%)$. 
Responden merasa sangat puas, puas, dan cukup puas karena petugas sudah memberikan informasi obat dengan baik, puas dengan kecepatan farmasis dalam menyiapkan obat (obat jadi : \pm 15 menit, puyer : \pm 20 menit, dan capsul : \pm 30 menit) dan merasa puas dengan kesiapsiagaan farmasis dalam memberikan pelayanan obat di Puskesmas Baraka Kecamatan Baraka Kabupaten Enrekang. Tetapi masih ada beberapa pasien yang merasa tidak puas, hal ini dikarenakan banyaknya pasien yang dilayani pada hari-hari tertentu sehingga tidak semua pasien dilayani dengan baik.

2. Responsiveness (Daya Tanggap), yaitu kemauan atau keinginan para karyawan untuk membantu dan memberikan jasa yang dibutuhkan pasien ( Jasfar, F., 2005 )

Hasil penelitian pada tabel 2 menunjukkan bahwa tanggapan responden terhadap petugas dalam memberikan pelayanan obat di Puskesmas Baraka Kecamatan Baraka Kabupaten Enrekang sudah merasa puas dengan jumlah persentase skor $67,8 \%$. Hal ini dapat dilihat dari 77 responden diperoleh jawaban sangat puas $(8,2 \%)$, puas $(43,8 \%)$, cukup puas $(14,9 \%)$, dan tidak puas $(0,8 \%)$.

Responden merasa sangat puas, puas, dan cukup puas karena farmasis yang bertugas dapat dengan tanggap menerima resep yang pasien serahkan, puas dengan kecepatan petugas farmasis dalam bertindak bila pasien membutuhkan sesuatu, dan dalam pelayanan obat di Puskesmas Baraka Kecamatan Baraka Kabupaten Enrekang. Tetapi masih ada beberapa pasien yang merasa tidak puas, hal ini dikarenakan banyaknya pasien yang dilayani pada hari-hari tertentu sehingga tidak semua pasien dilayani dengan baik.

3. Assurance (Jaminan), meliputi pengetahuan, kemampuan, ramah, sopan, dan sifat dapat dipercaya dari kontak personal untuk menhilangkan sifat keragu-raguan konsumen dan merasa terbebas dari bahaya dan resiko pasien ( Jasfar, F., 2005 ).
Hasil penelitian pada tabel 3 menunjukkan bahwa pasien merasa puas terhadap ketersediaan obat di Apotek Puskesmas Baraka, merasa puas dengan bahasa yang digunakan farmasis, dan merasa puas dengan pelayanan farmasis dalam hal kerapihan dan kebersihannya. Hal ini dapat dilihat dari 77 responden dengan jumlah persentase skor $69,2 \%$, dimana diperoleh jawaban sangat puas $(7,7 \%)$, puas $(47,4 \%)$, cukup puas $(13,6 \%)$, dan tidak puas $(0,45 \%)$. Tetapi masih ada beberapa pasien yang merasa tidak puas, hal ini dikarenakan banyaknya pasien yang dilayani pada hari-hari tertentu sehingga tidak semua pasien dilayani dengan baik.

4. Empaty (Kepedulian), yang meliputi sikap kontak pesonel maupun perusahaan untuk memahami kebutuhan maupun kesulitan, konsumen, komunikasi yang baik, perhatian pribadi, kemudian dalam melakukan komunikasi atau hubungan (Jasfar,F., 2005).

Hasil penelitian pada tabel 4 menunjukkan bahwa tanggapan responden terhadap sikap petugas dalam menanggapi pertanyaanpertanyaan dari pasien di Puskesmas Baraka Kecamatan Baraka Kabupaten Enrekang dilakukan dengan baik. Hal ini dapat dilihat dari 77 responden dengan jumlah persentase skor $66,7 \%$ dimana jawaban sangat puas $(8,2 \%)$, puas $39,6 \%)$, cukup puas $(18,1 \%)$, dan tidak puas $(0,7 \%)$.

Responden merasa sangat puas, puas, dan cukup puas dalam hal menanggapi pertanyaan-pertanyaan dari pasien, mengenai kesetiaan farmasis mendengarkan keluhan pasien, dan merasa puas terhadap kesopanan farmasis selama melayani pasie. Tetapi masih ada beberapa pasien yang merasa tidak puas, hal ini dikarenakan banyaknya pasien yang dilayani pada hari-hari tertentu sehingga tidak semua pasien dilayani dengan baik.

5. Tangibles ( Bukti Fisik), tersedianya fasilitas fisik, perlengkapan dan sarana komunikasi, dan lain-lain yang dapat dan harus ada dalam proses jasa. 
Penilaian terhadap dimensi ini dapat diperluas dalam bentuk hubungan dengan konsumen lain pengguna jasa (Jasfar,F., 2005).

Hasil penelitian pada tabel 5 menunjukkan bahwa tanggapan responden terhadap kenyamanan dalam ruang tunggu Apotek di Puskesmas Baraka Kecamatan Baraka Kabupaten Enrekang termasuk kategori puas. Hal ini dapat dilihat dari 77 responden dengan jumlah persentase skor $72,9 \%$ dimana diperoleh jawaban sangat puas (9\%), puas $(56,4 \%)$, cukup puas $(6,9 \%)$, dan tidak puas $(0,4 \%)$.

Responden merasa sangat puas, puas, dan cukup puas karena kenyamanan dalam ruang tunggu, baik dalam kebersihan Apotek, kenyamanan ruang tunggu, sertatersedianya tempat duduk untuk semua pasien-pasien sangatlah baik, namun masih ada pasien merasa tidak puas, dikarenakan pada saat itu pasien banyak sehingga tidak mendapatkan tempat duduk.

Keseluruhan hasil penelitian tentang Tingkat Kepuasan Pasien terhadap pelayanan obat di Puskesmas Baraka Kecamatan Baraka Kabupaten Enrekang diperoleh persentase skor 68,6 \% (Lihat tabel 6) berarti tingkat kepuasan pasien terhadap pelayanan obat di Puskesmas Baraka Kecamatan Baraka Kabupaten Enrekang termasuk kategori puas.

\section{PENUTUP}

Kesimpulan

Berdasarkan hasil penelitian dan pembahasan yang telah diuraikan, maka dapat ditarik kesimpulan bahwa tingkat kepuasan pasien terhadap pelayanan obat di Puskesmas Baraka Kecamatan Baraka Kabupaten Enrekang tahun 2017 termasuk kategori puas $(68,6 \%)$. Adapun tingkat kepuasan pasien ini yaitu sebagai berikut : Reability (Kehandalan) 66,4 \% = puas, Responsiveness (Daya Tanggap) 67,7 \% = puas, Assurance (Jaminan) 69,2 \% = puas, Emphaty (Kepedulian) 66,7 \% = puas, Tangible (Bukti Fisik) 72,9\%= puas.
Saran

Berdasarkan kesimpulan dari penelitian diatas dapat disarankan bahwa sebaiknya pelaksanaan pelayanan obat di Puskesmas Baraka Kecamatan Baraka Kabupaten Enrekang pada semua dimensi (Reability, Responsiveness, Assurance, Emphaty, Tangible) perlu dipertahankan bahkan ditingkatkan serta penambahan SDM yang terlatih sehingga dapat meningkatkan kepuasan pasien terhadap pelayanan kesehatan serta mewujudkan pelayanan yang berkualitas.

\section{DAFTAR PUSTAKA}

Anief, M., 2004, Manajemen Farmasi, : Yogyakarta : Gadjah Mada University

Anonim.,2011,Pelayanan Informasi Obat,http://tyutmahiwa.blogspot. com/2011/04/pelayanan informasi-obat-pio.html diakses tanggal 3 Januari 2016

Batubara, P.L., 2008, Farmakologi Dasar, edisi II : Jakarta : Lembaga Studi dan Konsultasui Farmakologi

Depkes RI., 2006, Pedoman Pelayanan Kefarmasian Di Puskesmas, Depkes RI : Jakarta

Ditjen Binfar \& Alkes., 2006, Pedoman Konseling Pelayanan Kefarmasian di Sarana Kesehatan.: Jakarta

Effendi, F \& Makhfudli., 2013, Keperawatan Kesehatan Komunitas Teori dan Praktik dalam Keperawatan : Jakarta

Eka, A., 2014, Hubungan Pelayanan Kefarmasian Dengan Kepuasan Pasien Menggunakan Jasa Apotek Di Kota Denpasar, Denpasar : Universitas Udayana Denpasar

Jasfar, F., 2005, Manajemen Jasa Pendekatan Terpadu, Bogor : Ghalia Indonesia

Katzung, B. G., 2007, Basic \& Clinical Pharmacology, Tenth Edition, United States : Lange Medical Publications 
Menteri Kesehatan Republik Indonesia 2010, Peraturan Menteri Kesehatan Nomor 193/Kab/B.VII/71. Tentang Pengertian Obat, Jakarta : Menkes RI

Kotler, 2005, Manajemen Pemasaran, Jakarta : PT. Indeks Kelompok Greamedia

Parasuraman, dkk., 2003, Pengaruh Kualitas Pelayanan Terhadap Kepercayaan. Journal Of Retailing, Vol.64, No.1
Pohan, I.S., 2006, Jaminan Mutu Pelayanan Kesehatan, Jakarta : EGC

Siregar, C.J.P, 2003, Farmasi Rumah Sakit Teori \& Penerapan, Jakarta : EGC

Sugiyono., 2005., Metode Penelitian Admninistrasi, Bandung : Alfabeta

Trihono., 2005, Manajemen Puskesmas Berbasis Paradigma Sehat, : Jakarta: Sagung Seto.

Umar, H., 2003, Metode Riset Perilaku Konsumen Jasa, Jakarta : Ghalia Indonesia. 